\title{
Effect of carburizing on fatigue behaviour in a type 316 austenitic stainless steel
}

\author{
K. Tokaji \& M. Akita \\ Department of Mechanical and Systems Engineering, \\ Gifu University, Japan
}

\begin{abstract}
The effect of carburizing on fatigue behaviour of smooth and notched specimens and corrosion fatigue behaviour was studied in a type 316 austenitic stainless steel. The fatigue strength of the smooth specimens was considerably increased by carburizing and the specimens with a thick case exhibited longer fatigue lives than the specimens with a thin case. The fatigue strength of the notched specimens was also increased by carburizing and the extent of increase in fatigue strength decreased with increasing stress concentration factor and then saturated. A slight increase in notch sensitivity by carburizing was seen. In $3 \% \mathrm{NaCl}$ aqueous solution, the carburized smooth specimens showed no reduction in fatigue strength, indicating the excellent corrosion resistance of the carburized case.
\end{abstract}

Keywords: fatigue strength, notch effect, corrosion fatigue, carburizing, case depth, austenitic stainless steel.

\section{Introduction}

In recent years, it has been strongly required to extend the service life of machines and structures due to economic and environmental reasons. To achieve this requirement, various surface engineering techniques have become major interest because they can provide additional properties such as high strength, thermal barrier, and corrosion and wear resistance.

Austenitic stainless steels have excellent corrosion resistance, but they posses relatively low strength and poor wear resistance. Therefore, it is significant to improve those properties by surface treatment. When surface-modified materials are applied to load-bearing components, fatigue properties are critical. Until 
now, the fatigue behaviour of austenitic stainless steels modified by shot peening [1-5], laser [6], dynamic ion mixing [7] and coating [8] has been reported. In addition to these techniques, a carburizing technique has been developed, which can apply to austenitic stainless steels without any loss of their advantages such as corrosion resistance and ductility [9]. Wear resistance and strength can also be improved by this method [9], but fatigue properties have not been studied.

In the present work, rotary bending fatigue tests were performed using carburized smooth and notched specimens of a type 316 austenitic stainless steel in laboratory air and in $3 \% \mathrm{NaCl}$ aqueous solution. Fatigue behaviour and fracture mechanisms of smooth specimens, notch effect and corrosion fatigue behaviour were discussed.

\section{Experimental details}

\subsection{Material and specimens}

The material used is a type 316 austenitic stainless steel of $16 \mathrm{~mm}$ diameter whose chemical composition (wt.\%) is $\mathrm{C} 0.05$, Si $0.35, \mathrm{Mn} 1.35, \mathrm{P} 0.033$, $\mathrm{S} 0.025$, Ni 10.1, Cr 16.9, Mo 2.11. The material was solution treated at $1353 \mathrm{~K}$ for $1 \mathrm{~h}$ followed by oil cooling, from which the following fatigue specimens were machined.

Smooth specimens of an hourglass shape with a minimum diameter of 5.5 $\mathrm{mm}$ were used. The stress concentration factor, $K_{\mathrm{t}}$, was 1.03 under bending. In notched specimens, a circumferential notch with a depth of $1 \mathrm{~mm}$ and three different notch radii, $\rho$, of $0.40 \mathrm{~mm}, 0.10 \mathrm{~mm}$ and $0.03 \mathrm{~mm}$ was introduced to the gauge section of $8 \mathrm{~mm}$ diameter, whose $K_{\mathrm{t}}$ values are 2.08, 3.55 and 6.50, respectively. After machining, the following surface treatment was applied to the fatigue specimens.

\subsection{Carburizing}

A modified gas-carburizing technique, which is called pionite treatment, was performed at a temperature below $773 \mathrm{~K}$ in a $\mathrm{CO}$ and $\mathrm{H}_{2}$ gas mixture [9]. During this process, a carbon-diffused zone is formed at the surface region with no $\mathrm{Cr}$ carbides where hardness is remarkably increased. This treatment can improve significantly wear resistance and strength without any loss of ductility and toughness of austenitic stainless steels [9].

In order to produce specimens with two different case depths, the treatment times, $t_{\mathrm{p}}$, of $15 \mathrm{~h}$ and $35 \mathrm{~h}$ were applied to the smooth specimens. Hereafter, the smooth specimens treated for $15 \mathrm{~h}$ and $35 \mathrm{~h}$ are denoted as the $15 \mathrm{~h}$ treated specimen and the $35 \mathrm{~h}$ treated specimen, respectively, and the specimen not subjected to the surface modification is referred to as the untreated specimen. Only $35 \mathrm{~h}$ treatment time was employed for the notched specimens.

\subsection{Procedures}

Fatigue tests were carried out using cantilever-type rotary bending fatigue testing machines operating at a frequency of $19 \mathrm{~Hz}$ in laboratory air and in $3 \% \mathrm{NaCl}$ 
aqueous solution. The solution was dropped continually onto the specimen surface by a pump from a reserved tank. Crack initiation and small crack growth were monitored with replication technique. After experiment, fracture surfaces were examined in detail by a scanning electron microscope (SEM).

\section{Results and discussion}

\subsection{Microstructure characterization}

Figure 1 shows the microstructures of the untreated and carburized specimens. In the untreated specimen, the microstructure consists of austenitic grains, while in the carburized specimen, a surface region that is clearly distinguished from the core can be recognized, which is the case formed by carburizing. As can be seen in the figure, the carburized case depths are approximately $20 \mu \mathrm{m}$ and $40 \mu \mathrm{m}$ for the $15 \mathrm{~h}$ and $35 \mathrm{~h}$ treated specimens, respectively. It has been indicated that no Cr-carbides were formed in the carburized case and the microstructure underneath the carburized case was the same austenitic microstructure as in the untreated specimens [9].
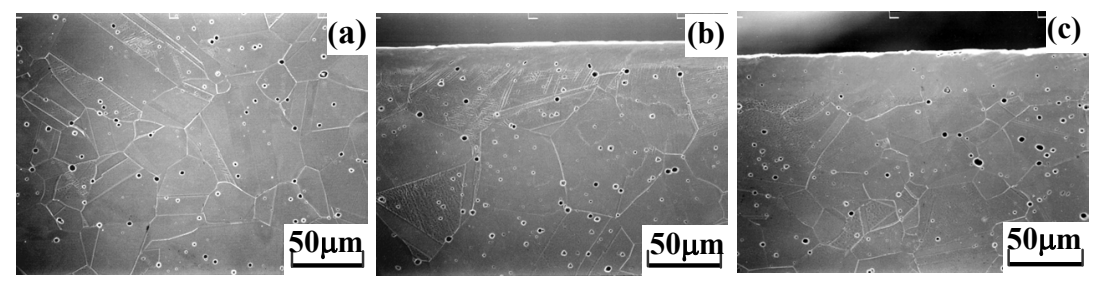

Figure 1: Microstructures: (a) untreated, (b) $t_{\mathrm{p}}=15 \mathrm{~h}$, (c) $t_{\mathrm{p}}=35 \mathrm{~h}$.

\subsection{Hardness profile and mechanical properties}

Vickers hardness profiles measured on the minimum cross section in the carburized smooth and notched specimens are represented in fig. 2 . The hardness at or near the surface attains to more than $800 \mathrm{HV}$ and $1000 \mathrm{HV}$ in the $15 \mathrm{~h}$ and $35 \mathrm{~h}$ treated specimens, respectively. Hardness rapidly decreases with increasing the distance from the surface and then reaches a constant value of approximately $172-220 H V$ that is the hardness of the core, i.e. the untreated specimen. The region of the increased hardness is $40-50 \mu \mathrm{m}$ regardless of treatment time and notch geometry. As can seen in fig. 1, however, the case depth depended on treatment time, thus the case depth, $d_{\mathrm{p}}$, was defined as the depth established by the microstructure characterization.

The mechanical properties are listed in table 1. In the carburized specimens, tensile strength increases and ductility decreases compared with the untreated specimen and with increasing treatment time, but the differences between the untreated and carburized specimens are small. 


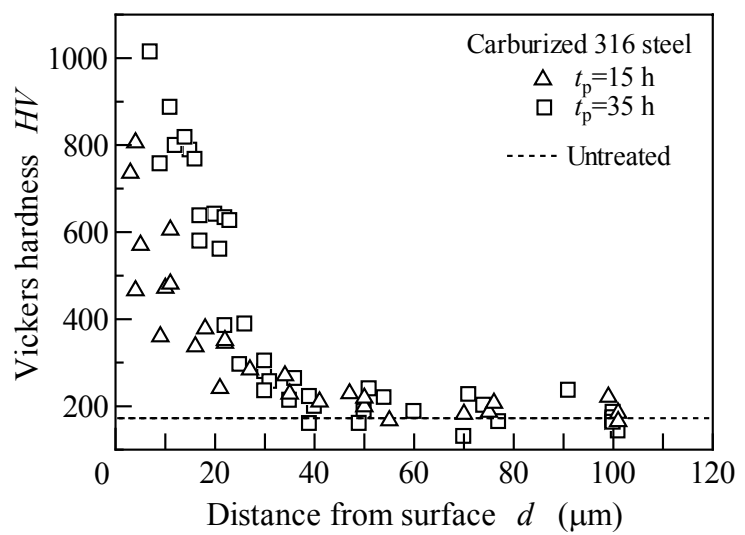

(a) Smooth specimens

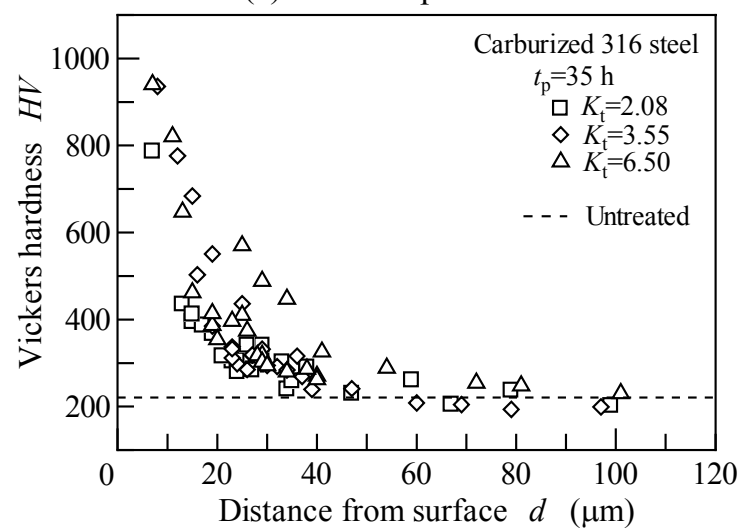

(b) Notched specimens

Figure 2: $\quad$ Vickers hardness profiles.

Table 1: $\quad$ Mechanical properties.

\begin{tabular}{ccccc}
\hline $\begin{array}{c}\text { Treatment } \\
\text { time } \\
t_{\mathrm{p}}\end{array}$ & $\begin{array}{c}\text { Proof } \\
\text { stress }\end{array}$ & $\begin{array}{c}\text { Tensile } \\
\text { strength }\end{array}$ & $\begin{array}{c}\text { Elongation Reduction } \\
\text { of area }\end{array}$ \\
& $(\mathrm{MPa})$ & $\sigma_{\mathrm{B}}$ & $\phi$ & $\psi$ \\
$(\mathrm{MPa})$ & $(\%)$ & $(\%)$ \\
\hline Untreated & 299 & 576 & 67 & 77 \\
$15 \mathrm{~h}$ & & 579 & 61 & 74 \\
$35 \mathrm{~h}$ & & 581 & 57 & 72 \\
\hline
\end{tabular}

\subsection{Fatigue behaviour of smooth specimens}

The $S$ - $N$ diagram is shown in fig. 3. It can be seen that the fatigue strength is considerably increased by carburizing. The case depth dependence of fatigue 
strength is slightly seen in the finite life region, where the $35 \mathrm{~h}$ treated specimen exhibits slightly longer fatigue lives than the $15 \mathrm{~h}$ treated specimen, while there is no discernible difference in the fatigue limit that is $390 \mathrm{MPa}$ for both carburized specimens. The fatigue limit of the untreated specimen is $300 \mathrm{MPa}$, thus the improvement by $30 \%$ is achieved with the modified carburizing employed in the present study. Fatigue tests at the fatigue limit were continued to $N=5 \times 10^{7}$ cycles, but no fatigue failure took place.
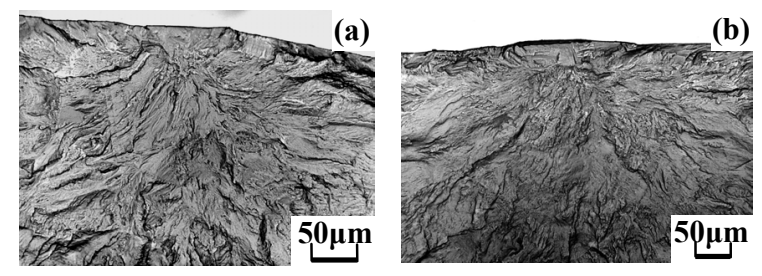

Figure 3: $S-N$ diagram for untreated and carburized smooth specimens in laboratory air.

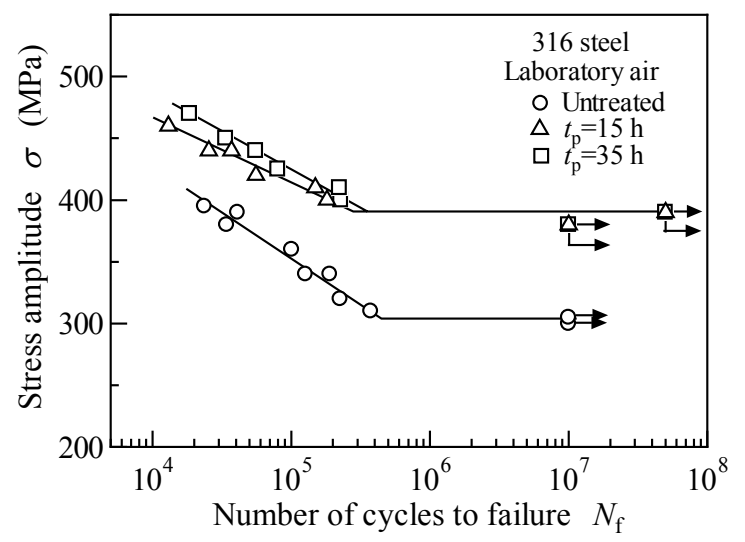

Figure 4: $\quad$ SEM micrographs of fracture surfaces near crack initiation site in laboratory air: (a) $t_{\mathrm{p}}=15 \mathrm{~h}(\sigma=440 \mathrm{MPa}),(\mathrm{b}) t_{\mathrm{p}}=35 \mathrm{~h}(\sigma=410 \mathrm{MPa})$.

In the untreated specimen, fatigue cracks generated at the specimen surface due to cyclic slip deformation. Figure 4 reveals typical examples of SEM micrographs of fracture surfaces near the crack initiation site in the carburized specimens. Regardless of applied stress level, cracks initiate underneath the carburized case, i.e. at or near the boundary between the carburized case and the core. Similar subsurface crack initiation was also observed in austenitic stainless steels treated by shot peening [2-4]. A close examination reveals the presence of a smooth facet in the carburized case just above the subsurface crack initiation site, particularly remarkable in the $35 \mathrm{~h}$ treated specimens. It is also worth noting that there exists a fish-eye like pattern that extends predominantly into the core and the sizes are approximately $150 \mu \mathrm{m}$ in the radial direction. 
As shown in fig. 3, the fatigue strengths of the carburized specimens were improved considerably compared with the untreated specimens and the fatigue limit increased by $30 \%$ by carburizing. This is due to suppression of slip deformation at the specimen surface because of remarkable hardness increase, i.e. the resistance to crack initiation is significantly enhanced in the carburized case. Therefore, crack initiation becomes difficult to occur at the surface and then moves to subsurface between the carburized case and the core. The fatigue limits of the carburized specimens were $390 \mathrm{MPa}$ that is considerably higher than the proof stress $(299 \mathrm{MPa})$ and the fatigue limit $(300 \mathrm{MPa})$ of the untreated specimens. This is because the limiting stress for crack initiation could be enhanced due to constraint of deformation by the hard carburized case.

In the finite life region, the effect of treatment time, i.e. case depth on fatigue strength was slightly seen where the fatigue lives of the specimen with thick case were longer than those of the specimen with thin case. This may also be due to enhancement of the crack initiation resistance and constraint of the carburized case to small crack growth because of increased hardness of the carburized case with increasing treatment time.

\subsection{Notch fatigue behaviour}

The $S-N$ diagram characterized in terms of nominal stress amplitude for the untreated and carburized notched specimens is shown in fig. 5. As commonly observed, fatigue strength decreases with increasing $K_{\mathrm{t}}$ in both the untreated and carburized conditions, but the differences in fatigue strength between the notched specimens with $K_{\mathrm{t}}=3.55$ and 6.50 become small. In the carburized specimens, the fatigue strengths increase significantly compared with the untreated specimens. As described previously, this is due to the suppression of slip deformation at the notch root surface because of remarkable hardness increase. It should be noted that the extent of increase in fatigue strength is largest in the smooth specimen and decreases with increasing $K_{\mathrm{t}}$, then tends to saturate at $K_{\mathrm{t}}=3.55$. It is also worth noting that no non-propagating cracks were seen in all run-out notched specimens in both the untreated and carburized conditions.

In the untreated specimens, it was found that cracks initiated at the notch root surface due to cyclic slip deformation. In the carburized specimens with $K_{\mathrm{t}}=2.08$ and 3.55, the crack initiation behaviour depended on applied stress level. At high applied stresses, cracks initiated at the notch root surface, while at low applied stresses, underneath the carburized case. Such examples are revealed in fig. 6, where cracks initiated due to cyclic slip deformation underneath the carburized case and then immediately propagated to the surface. On the contrary, in the carburized notched specimens with $K_{\mathrm{t}}=6.50$, cracks generated at the notch root surface regardless of applied stress level.

The relationship between fatigue strength reduction factor, $K_{\mathrm{f}}$, and $K_{\mathrm{t}}$ is represented in fig. 7, where $K_{\mathrm{f}}$ is defined as the ratio of the fatigue limit for the smooth specimen, $\sigma_{\mathrm{wo}}$, to that for the notched specimens, $\sigma_{\mathrm{wk}}$. The $K_{\mathrm{f}}$ values for the untreated condition are considerably lower than $K_{\mathrm{t}}$ and the difference between both increases with increasing $K_{\mathrm{t}}$, then tends to saturate at high $K_{\mathrm{t}}$ values [10]. This implies that the present material has very low notch sensitivity. 
Similar results have been reported on type 304 and 316 austenitic stainless steels [10-13]. On the other hand, the $K_{\mathrm{f}}$ values for the carburized condition have the same $K_{\mathrm{t}}$ dependence as observed in the untreated condition, but are slightly larger in the entire $K_{\mathrm{t}}$ range studied. This indicates that the notch sensitivity of the present material is only slightly increased by carburizing.

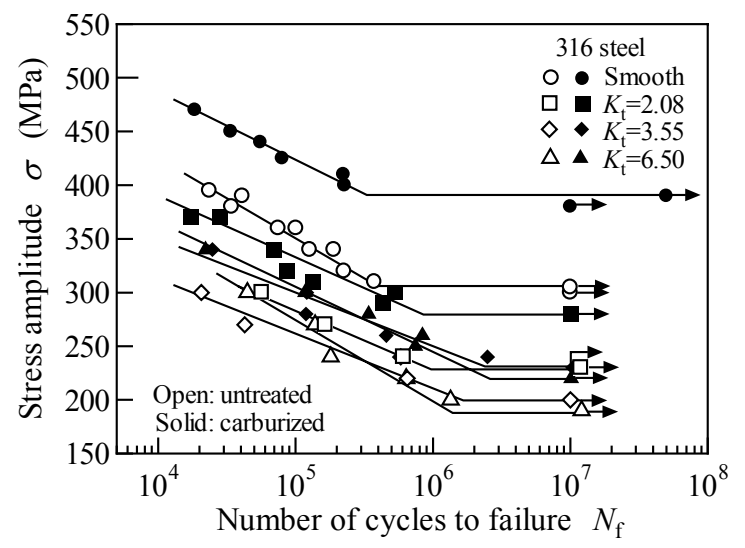

Figure 5: $S-N$ diagram for untreated and carburized notched specimens characterized in terms of nominal stress amplitude in laboratory air.
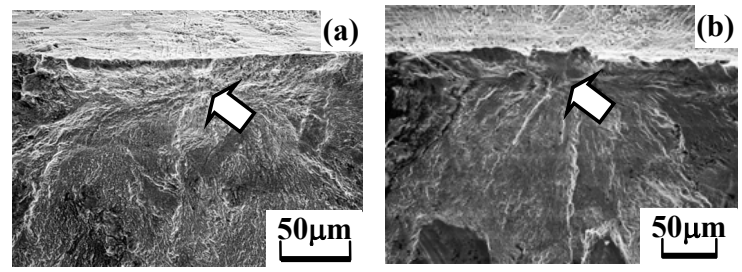

Figure 6: SEM micrographs showing subsurface crack initiation in carburized notched specimens: (a) $K_{\mathrm{t}}=2.08 \quad(\sigma=300 \mathrm{MPa}),($ b) $K_{\mathrm{t}}=3.55(\sigma=300 \mathrm{MPa})$. Arrows indicate the crack origin.

\subsection{Corrosion fatigue behaviour}

Figure 8 shows the $S$ - $N$ diagram for smooth specimens in $3 \% \mathrm{NaCl}$ aqueous solution. For comparison, the $S-N$ curves in laboratory air are also included without experimental data points. In the untreated specimen, the fatigue strength in $3 \% \mathrm{NaCl}$ aqueous solution is lower than that in laboratory air and the reduction increases gradually with decreasing stress level. This is the well-known corrosion fatigue behaviour. On the contrary, the carburized specimens exhibit longer fatigue lives at high applied stresses than in laboratory air, but tend to exhibit nearly the same fatigue lives as in laboratory air with decreasing applied stress level. In addition, the fatigue limit seems to exist even in the corrosive environment within the range of experiment. 


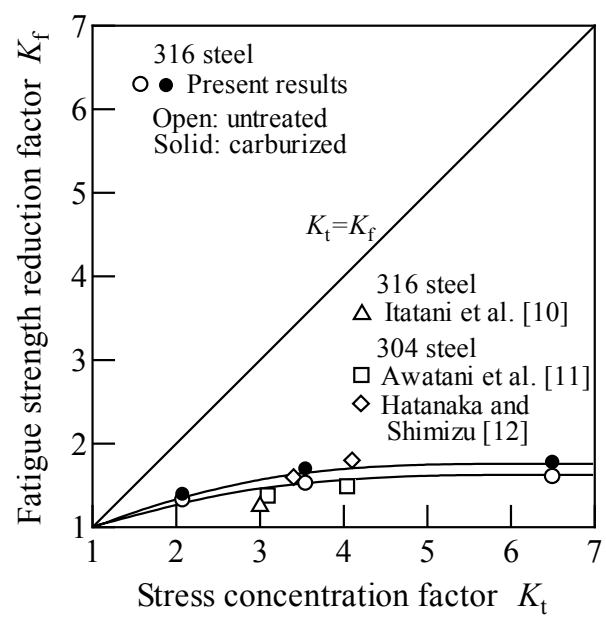

Figure 7: Relationship between fatigue strength reduction factor and stress concentration factor.

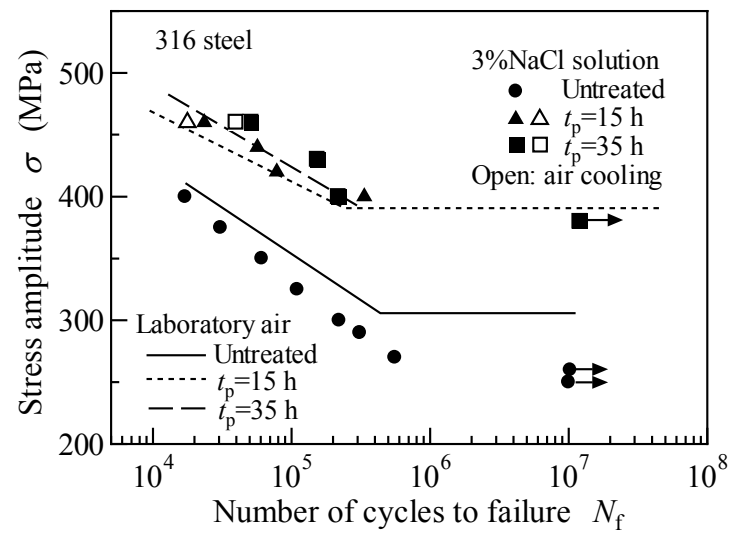

Figure 8: $S-N$ diagram for untreated and carburized smooth specimens in $3 \% \mathrm{NaCl}$ aqueous solution.

In the untreated specimens, cracks initiated at the specimen surface, while in the carburized specimens, always generated underneath the carburized case even in $3 \% \mathrm{NaCl}$ aqueous solution. A brittle facet was seen in the case just above the subsurface crack initiation site, which has occurred due to crack initiation and subsequent growth into the interior of the specimens.

The increase of fatigue life at high applied stresses in $3 \% \mathrm{NaCl}$ aqueous solution is believed to be due to suppression of temperature raise resulting from stress cycling. The surface temperature was not measured in the present study, but significant temperature raise has also been indicated in austenitic stainless 
steel [3, 14, 15]. Thus, a few additional fatigue tests were performed in laboratory air using the carburized specimens that were forced to cool by air. The obtained data are plotted in fig. 8. The fatigue lives are slightly longer than in laboratory air, but shorter than in $3 \% \mathrm{NaCl}$ aqueous solution. These results seem reasonable, because the cooling effect by the solution is much larger than by air.

As indicated above, it should be emphasized that the specimens hardened by the modified carburizing showed no reduction of fatigue strength in aqueous corrosive environment. Since the fatigue strength of the untreated specimen decreased significantly in the corrosive environment, the modified carburizing can prevent the decrease of corrosion fatigue strength.

\section{Conclusions}

In the present work, the effect of carburizing on fatigue behaviour of smooth and notched specimens and corrosion fatigue behaviour was studied in a type 316 austenitic stainless steel. The main conclusions can be made as follows.

(1) The fatigue strength of the carburized smooth specimens increased considerably compared with the untreated specimen. The case depth dependence of fatigue strength was seen in the finite life region where the fatigue lives of the specimen with thick case were slightly longer that those of the specimen with thin case, while there was no discernible difference in the fatigue limit.

(2) The fatigue strength of the notched specimens was increased by carburizing and the extent of increase decreased with increasing stress concentration factor and then saturated. Both the untreated and carburized specimens indicated significantly low notch sensitivity, with a slight increase by carburizing.

(3) In $3 \% \mathrm{NaCl}$ aqueous solution, the carburized specimens exhibited no reduction of fatigue strength, indicating excellent corrosion resistance of the carburized case.

(4) In the carburized smooth specimens, cracks initiated at subsurface underneath the carburized case regardless of applied stress level and environment. In the carburized notched specimens, the crack initiation behaviour was dependent on applied stress level and stress concentration factor. In the specimens with moderate stress concentration factors, crack initiation occurred at the notch root surface at high applied stresses, while underneath the carburized case at low applied stresses. In the specimens with s severe stress concentration factor, cracks initiated at the notch root surface regardless applied stress level.

\section{References}

[1] Hayashi, M. \& Enomoto, K., Effect of preliminary surface working on fatigue strength of type 304 stainless steel in air and pure water at $288^{\circ} \mathrm{C}$. J. Soc. Mat. Sci. Jpn, 45, pp.1107-1112, 1996.

[2] Masaki, K., Ochi, Y. \& Ishii, A., Behaviors of hardness distribution, residual stress distribution and fatigue cracks during the fatigue process. Mater. Sci. Research Int., 4, pp.200-205, 1998. 
[3] Ochi, Y. \& Masaki, K., Improvement of fatigue strength and fracture surface morphology of hard shot-peened type 316L steel. Proc. of the $12^{\text {th }}$ Bienniel Conference on Fracture, eds. M.W. Brown, E.R. de los Rios \& K.J. Miller, EMAS: West Midlands, I, pp.127-132, 1998.

[4] Masaki, K., Ochi, Y. \& Matsumura, T., Estimation of high cycle fatigue limit of hard shot peened austenitic stainless steel. Proc. of the $10^{\text {th }}$ Int. Congress on Fracture, Elsevier Science: Oxford, CD-ROM, 2001.

[5] Masaki, K., Ochi, Y. \& Matsumura, T., The effects of hard shot-peening on high cycle fatigue properties of SUS316L steel. Proc. of the $7^{\text {th }}$ Int. Fatigue Congress, eds. X.R. Wu \& Z.G. Wang, Higher Education Press: Beijing, EMAS: West Midlands, III, pp.1219-1224, 1999.

[6] Stamm, H., Holzwarth, U., Boerman, D.J., Dos Santos Marques, F., Olchini, A. \& Zausch, R., Effect of laser surface treatment on high cycle fatigue of AISI316 stainless steel. Fatigue Fract. Eng. Mater. Struct., 19, pp.985-995, 1996.

[7] Villechaise, P., Mendez, J. \& Delafond, J., Improvement in fatigue resistance of $316 \mathrm{~L}$ stainless steel and copper by aluminum coating with dynamic ion mixing. Surf. Modification Technol. IV, pp.335-347, 1991.

[8] Berrios, J.A., Teer, D.G. \& Puchi-Cabrera, E.S., Fatigue properties of a 316L stainless steel coated with different TiNx deposites. Surf. Coat. Technol., 148, pp.179-190, 2001.

[9] Aoki, K. \& Kitano, K., Surface hardening for austenitic stainless steels based on carbon solid solution. Surface Eng., 18, pp.462-463, 2002.

[10] Itatani, M., Asano, K. \& Iida, K., Fatigue strength of notched austenitic stainless steel for nuclear power component. ASME PVP 374, pp.145-152, 1998.

[11] Awatani, J., Katagiri, K., Shiraishi, T. \& Matsuyama, T., Fatigue character of stainless steel related to nonpropagating cracks. J. Soc. Mater. Sci., Jpn, 25, pp.151-156, 1976.

[12] Hatanaka, K. \& Shimizu, S., Fatigue strength in long life range and nonpropagating crack in SUS304 type stainless steel. Bulletin of the JSME, 25, pp.1859-1866, 1982.

[13] Linder, J. \& Larsson, M., Notch sensitivity of austenitic and duplex stainless sheet steels. Internal report Swedish Institute for Metal Research, IM-3491, 1997.

[14] Tokaji, K, Ando, Z. \& Mizutani, H., Fatigue strength of austenitic stainless steel in various environments: initiation, density and distribution, and growth of small fatigue cracks. J. Soc. Mater. Sci., Jpn, 34, pp.816822, 1985.

[15] Ogawa, T., Tokaji, K. \& Kinpara, D., High cycle fatigue properties of SUS304 stainless steel under load-increasing conditions. Trans. Japan Soc. Mech. Engrs, 65, pp.1684-1689, 1999. 